Article

\title{
The King Abdulaziz University (KAU) Pandemic Framework: A Methodological Approach to Leverage Social Media for the Sustainable Management of Higher Education in Crisis
}

\author{
Abdulrahman Obaid AI-Youbi, Abdulmonem Al-Hayani, Hisham J. Bardesi, \\ Mohammed Basheri $\mathbb{D}^{\mathbb{D}}$, Miltiadis D. Lytras $\mathbb{D}$ and Naif Radi Aljohani* \\ King Abdulaziz University, Jeddah 21589, Saudi Arabia; aalyoubi@kau.edu.sa (A.O.A.-Y.); \\ aalhayani@kau.edu.sa (A.A.-H.); hbardesi@kau.edu.sa (H.J.B.); mbasheri@kau.edu.sa (M.B.); \\ mlytras@acg.edu (M.D.L.) \\ * Correspondence: nraljohani@kau.edu.sa
}

Received: 16 April 2020; Accepted: 15 May 2020; Published: 26 May 2020

\begin{abstract}
The recent pandemic has raised significant challenges worldwide. In higher education, the necessity to adopt efficient strategies to sustain education during the crisis is mobilizing diverse, complementary, and integrative action in response. In this research article, we rise to the challenge of designing and implementing a transparent strategy for social media awareness at King Abdulaziz University (KAU). We introduce a framework for social media impact, termed the KAU Pandemic Framework. This includes the factors with the most important role in enhancing the deployment of social media in crisis in order to minimize the negative impact on education's sustainability. We used a mixed-methods approach, integrating quantitative statistical analyses of social media data and online surveys and qualitative interviews in such a way as to construct a comprehensive framework. The results show that a methodological framework can be justified and that Twitter contributes significantly to six areas: administrative resilience; education sustainability; community responsibility; positive sentiment; community bonds; and delivery of promised value. The components of our proposed methodological framework integrate five pillars of the strategic adoption of social media: social media governance; social media resilience; social media utilization; decision-making capability; and institutional strategy. Finally, we show that the KAU Pandemic Framework can be used as strategic decision-making tool for the analysis of the gaps and inefficiencies in any social media plan that is deployed and the management challenges arising from the pandemic.
\end{abstract}

Keywords: pandemic; social media; social impact; higher education; framework; best practices; COVID-19; King Abdulaziz University; administration

\section{Introduction}

\subsection{Higher Education Challenges in Coronavirus Disease (COVID-19) Times}

Higher education institutions are facing various challenges at this time, related to the delivery of top-quality education and the utilization of their resources and competencies. The recent pandemic emergency has brought forward two further significant shifts: traditional academic institutions with slow-moving processes and bureaucracy must adopt fast to the new conditions and set up efficient communication and awareness channels for diverse stakeholders. At the same time, new technologies, for example social media, are revolutionizing traditional communication [1-3]. In this 
context, this study emphasizes the adoption strategy for social media at a leading academic institution, King Abdulaziz University (KAU) in Saudi Arabia.

The current coronavirus disease-COVID-19 pandemic is having a tremendous impact on the strategies and procedures of higher education institutions worldwide. Some aspects of this change are summarized in the following paragraphs. One of the most critical implications is the need both to manage the communication of significant knowledge and messages to key stakeholders fast and effectively and without compromising trust in the institution, and to increase its capacity for an effective response to pandemic emergency management.

From the other side, the rapid transition from face-to-face to online training in a very short period is challenging communication structures and flows between and among higher education administration, faculty, students, alumni, the student community and their families and governmental observatory bodies.

From a technical point of view, the use of emerging or streamline technologies such as social media and web-conferencing platforms raises significant issues relating to codes of ethics, privacy protection, data regulation, and security, and many others [4-6]. In the context of a well-established academic institution with thousands of students and faculty members, there is a critical need to specify transparent procedures on the use of technological resources, data, and procedures.

The quality of management in higher education is related to its capacity to deploy novel tools and services for collecting and analyzing data to enhance decision-making. Big data technologies, as well as analytics and data mining, including text mining and sentiment analysis, provide higher education with a new pool of sophisticated decision-making capabilities [2,6,7].

In the next paragraph, we present the governance of social media utilization in KAU. This provides this study with access to critical institutional data on the use of Twitter during this emergency.

\subsection{Governance of Social Media Utilization at KAU}

KAU has more than 120,000 students enrolled in 185 different majors, and offers diplomas, bachelor's degrees, master's degrees, and doctoral degrees. KAU has 28 colleges, 28 centers of excellence, 5 specialized institutions, 9 deanships, and 24 supporting centers for educational and research activities.

Almost all Saudi universities use Twitter for multiple purposes, mainly to reach large audiences in a short period of time. Universities can not only reach their students, but also share relevant news items, such as academic achievements and distinguished awards in Saudi society. However, although the use of Twitter might seem to represent a positive, it can also have a negative impact if it is not used in an organized and strategic manner. Social media gives users the freedom to participate and hold open discussions on many topics without imposing any restrictions. In many cases, it is up to individuals to decide on the suitability of the content that they would like to share with an audience.

The freedom of sharing individual views using an official university account can be limited. For instance, society may hold KAU responsible for a tweet that is perceived as negative, for any reason, and this would be not only a legal risk, but also damaging to KAU's academic reputation. Therefore, to govern the utilization of social media, the KAU university has established the KAU Web Observatory Centre in 2014 motivated by the idea of Web observatories [8]. The KAU Web Observatory Center has authored a code of ethics to govern and regulate the use of social media by all accounts that represent KAU on social media platforms. This code has been approved by higher administration at KAU and implemented for the past three years. It gives general guidance on how the accounts and employees that represent the University should behave. In addition, it constitutes a group of legal guidelines on avoiding what may bring harm to the University and specifying what is permissible under Saudi Law and regulations. Finally, the KAU code of ethics contains instructions for handling many known issues, such as harassment, safety, and conflict of interests.

The KAU Web Observatory Centre is a research center that strives to measure the impact of social media on higher education. One of the essential duties of KAU's Web Observatory Center is to provide the University and its members with research-informed evidence and guidelines on ways to 
make use of social media in the educational domain. In addition, it encourages the implementation of the KAU code of ethics by providing continuous short courses on the code and the best ways to implement its guidelines. Finally, it provides several types of analytical reports. Weekly reports show the performance of the University accounts against a group of predefined key performance indicators (KPIs) that are shared with all responsible for managing University accounts. Monthly reports highlight the main University events and their members, along with a statistical evaluation of the interaction with these events and the crowd's sentiments, a group of situational reports on specific events, and reports on hashtags relating to specific academic events at KAU. These reports play a role in enhancing the awareness of the individuals responsible for managing the University's official accounts in such a way as to help them to measure the impact of their social media activities and to send a focused message, tailored to their duty to promote KAU's departments.

This article is organized as follows: Section 2 presents a critical literature review on the use of social media in academic institutions in time of crisis. In Section 3, we present the overview of our research methodology composed of our research model and the research objectives. Analysis of the three combined research methods is in Section 4, including statistical analysis of Social Media (Twitter) Content in Section 4.1, qualitative analysis in Section 4.2 and quantitative analysis in Section 4.3. The main discussion and key findings are presented in Section 5, relating to the five research objectives of our research. The key contribution of our research, the KAU Pandemic Framework, is then summarized in Section 6. Finally, in Section 7, we present the conclusions and future research directions for this work.

\section{Literature Review: Analyzing the Use of Social Media by Academic Institutions in a Pandemic}

This study promotes multidisciplinary research grounded on the intersection of the disciplines of social media, higher education administration, and data science. In recent literature, there has been an increasing body of knowledge relating to the wide adoption of social media and Twitter for communication in higher education. Additionally, pandemic emergency management is a well-defined domain with significant contributions from diverse scientific communities $[9,10]$. In our study, these two research domains are the reference disciplines. In this section, we elaborate on selected literature that contributes to our research model.

\subsection{Social Media Utilization in Academic Institutions}

In the rapidly expanding discussion on the use of Twitter in higher education, several complementary studies have provided fertile ground for further investigation (Table 1). In a study on how colleges and universities deploy Twitter, Linvill et al. [11] found that most higher education institutions use Twitter as a monolithic, inflexible, and static means of communication. They analyzed the absence of non-dialogic communication and concluded that Twitter represents a limitation to the impact of social media if its use as a single newsfeed is not the optimal way to deploy social media. In our study, this poses a key requirement from the outset. We intend to build a methodological framework for the dialogic, interactive use of Twitter in higher education institutions, and we focus on the case of KAU in a pandemic.

In a relevant study, Palmer [12] focused on the adoption of Twitter for Australian university communications with stakeholders. The main purpose of the study was to understand what makes this communication more efficient in terms of promoting a university's communication objectives. The author proposed a visualization method. In our study, the concept of efficiency is critical. The adoption of social media is studied through the lens of its capacity to serve the institutional goals. Especially in the context of the current pandemic emergency, the component of efficiency requires a well-defined study of the institution's strategic goals and objectives. It is vital to investigate how KAU deploys the external Twitter accounts of institutions and stakeholders in order to execute its own social media strategy for impact.

Bélanger et al. [13], in another key study, analyzed the way that Canadian universities use social media to promote their branding. One of the most interesting findings was that individual contributions 
to social media and the discussions that they initiate have a critical impact. In our study's context of analyzing the impact of social media on pandemic emergency management, this is an additional level of analysis. We are concerned with the interactions of individuals, for instance the students, faculty and, administrators, and their capacity to promote further efficient and creative communication.

Another critical aspect of the literature is higher education institutions' use of Twitter as social media. In a recent study by Kimmons et al. [14], by adopting advanced data mining techniques, the authors analyzed 5.7 million tweets by higher education institutions in the United States. They concluded that, in most cases, Twitter communication is limited and monologic, and that knowledge is aggregated through a limited ecosystem of trusted external web resources. In our study, we are investigating an institutional strategy for social media adoption that goes beyond our main finding that Twitter is not being used to promote action.

Another aspect in the literature is related to governance and security related to the use of social media in academic institutions. An overview of the literature review regarding the adoption of social media by academic institutions can be viewed in Table 1. In a relevant study, Tripathi [15] found that most Indian universities have an unofficial presence on social media but that there are significant concerns regarding security and governance. In the context of a pandemic, due to the features of knowledge dissemination, both accuracy and trust in the resources and knowledge are critical. In an academic institution such as KAU, it is vital that official, trusted communication is secured. In the same direction, Otto and Williams [16] tried to understand how 24 universities adopt official Twitter accounts in daily practice. The key finding was that even though most institutions have an official account there is only rather limited understanding about the added value of using Twitter in daily practice and for university services.

Table 1. Overview of literature review for the adoption of social media by academic institutions.

\begin{tabular}{|c|c|c|c|}
\hline & \multicolumn{3}{|c|}{ Literature Review } \\
\hline Author(s) & Title of Article & Key Contribution & Impact on Our Research Model \\
\hline $\begin{array}{l}\text { Linvill et al. } \\
\text { (2012) }\end{array}$ & $\begin{array}{l}\text { Colleges' and } \\
\text { Universities' Use of } \\
\text { Twitter: A } \\
\text { Content Analysis }\end{array}$ & $\begin{array}{l}\text { It was found that institutions are not employing } \\
\text { Twitter in a dialogic way and, instead, they are } \\
\text { employing it primarily as an institutional news feed } \\
\text { to a general audience. }\end{array}$ & $\begin{array}{l}\text { There is a key inquiry for dialogic } \\
\text { Twitter use in higher education. }\end{array}$ \\
\hline Palmer (2013) & $\begin{array}{l}\text { Characterization of } \\
\text { the Use of Twitter by } \\
\text { Australian } \\
\text { Universities }\end{array}$ & $\begin{array}{c}\text { In this study, a two-year analysis is conducted of the } \\
\text { adoption of Twitter by Australian universities with } \\
\text { stakeholders in their environment. A visualization } \\
\text { method is proposed for more } \\
\text { efficient communication. }\end{array}$ & $\begin{array}{l}\text { The determinants of effective } \\
\text { communication are also in the } \\
\text { focus of our research. We want to } \\
\text { build a framework for social } \\
\text { media impact in higher } \\
\text { education institutions. }\end{array}$ \\
\hline $\begin{array}{l}\text { Bélanger et al. } \\
\qquad(2014)\end{array}$ & $\begin{array}{l}\text { How Canadian } \\
\text { Universities Use } \\
\text { Social Media to } \\
\text { Brand Themselves }\end{array}$ & $\begin{array}{l}\text { Authors analyze how Canadian universities promote } \\
\text { their brand by deploying Twitter. In this study also is } \\
\text { a critical insight that, beyond institutional } \\
\text { contributions, individuals and students contribute to } \\
\text { the branding with their own perceptions and } \\
\text { contributions on social media. }\end{array}$ & $\begin{array}{l}\text { We have to take into account the } \\
\text { significant impact of Twitter and } \\
\text { social media on perceptions and } \\
\text { branding, especially in times of } \\
\text { pandemic emergency. }\end{array}$ \\
\hline $\begin{array}{l}\text { Kimmons et al. } \\
\text { (2016) }\end{array}$ & $\begin{array}{l}\text { Institutional Uses of } \\
\text { Twitter in US } \\
\text { Higher Education }\end{array}$ & $\begin{array}{l}\text { Authors analyzed } 5.7 \text { million institutional tweets and } \\
\text { concluded that in most cases universities use Twitter } \\
\text { in a monologic, static way to disseminate content } \\
\text { from a limited ecosystem of external resources, } \\
\text { communicating neutral or positive sentiment. }\end{array}$ & $\begin{array}{l}\text { Our proposed institutional } \\
\text { framework for the strategic } \\
\text { impact of social media (SM) needs } \\
\text { to investigate value-adding } \\
\text { components for value delivery } \\
\text { through Twitter. }\end{array}$ \\
\hline Tripathi (2016) & $\begin{array}{l}\text { 'Unofficial' Presence } \\
\text { of Higher Education } \\
\text { Institutions in India } \\
\text { on Social Media: } \\
\text { Good or Bad? }\end{array}$ & $\begin{array}{l}\text { Authors study the unofficial presence of universities } \\
\text { in India, in social media, with focus on Facebook and } \\
\text { Twitter. They conclude that there is a significant } \\
\text { presence, with main concerns related to branding } \\
\text { and security. }\end{array}$ & $\begin{array}{l}\text { Institutional presence in SM } \\
\text { requires governance and a code of } \\
\text { ethics developed by institutional } \\
\text { centers for SM management. }\end{array}$ \\
\hline
\end{tabular}


This is an interesting finding for our study. We are concerned with justifying the value-adding components of a strategic impact framework for official institutional use of social media in the context of a pandemic emergency. Twitter is presented in the literature as a form of social media that is effective for initiating discussions and prompting interaction. In our study's case, pandemic emergency management requires an integrated strategy to respond to various users' requests and questions.

In Figure 1, below, we provide a constructive interpretation of the relevant literature review, related to the use of Twitter and social media from universities and colleges. This is one of the key aspects of our research problem. Our intention to construct a methodological framework for the strategic social impact of social media in academia is directly related to the issues depicted in Figure 1.

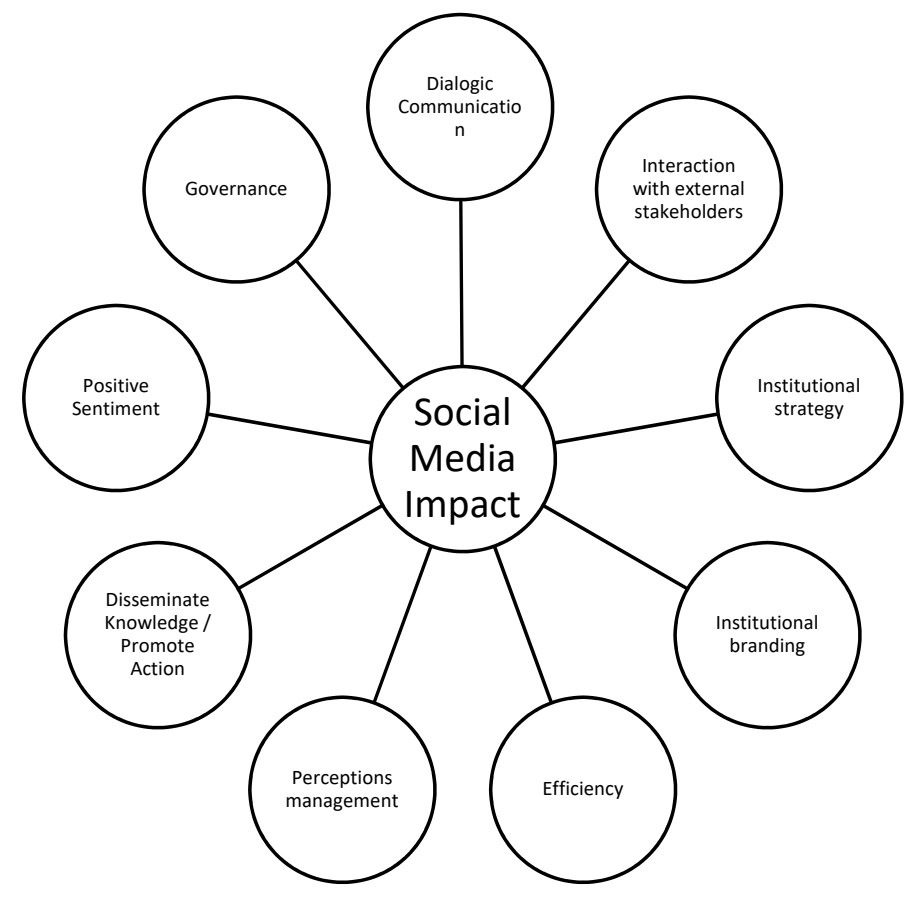

Figure 1. Research problem aspects.

Key Implications for Social Media Utilization in Academic Institutions

The critical literature review of social media use in the previous section is constructively interpreted here. A key aspect of our contribution is related to the main dimensions of a potential social media impact framework for higher education. As discussed in previous paragraphs, the social media impact in universities and colleges worldwide must take into consideration the following parameters:

Dialogic communication: It is necessary to investigate how Twitter and social media promote the ideas of dialogic communication. A static dissemination of knowledge and awareness may be significant, but interaction and engagement are of crucial importance.

Interaction with external stakeholders: Academic institutions' official use of Twitter, and social media in general, must involve trusted resources and information from a network of external stakeholders. This is extremely important in the case of a pandemic emergency, where trusted knowledge is related to official communications by organizations such as the World Health Organization and national ministries.

Institutional strategy: The strategic use of social media in universities and colleges must be founded on solid institutional strategies that are capable of governing and utilizing resources. A key aspect of this strategy is Institutional branding, which permits the strategy to capitalize on added value for the reputation of academic institutions. It is important for our study to understand how the efficient management of social media contributes to positive perceptions of the academic community. Thus, 
Efficiency and Perceptions management is a critical pillar of any strategy for the use of Twitter in academia, and it is a key aspect of the problem addressed by this research.

Governance of social media in universities and colleges is a critical success factor of the strategic impact of social media. It seems that there is a direct link between governance and the Dissemination strategies and promotion of active engagement. In the same context, the continuous monitoring of positive sentiment is another direction for efficiency measurement that is of key importance to our study.

In the next section of our literature review, we present a selective critical review of scientific works related to pandemic management. As explained at the beginning of this section, our study focuses on the analysis of social media's impact on management during a pandemic.

\subsection{Pandemic Management Literature Review}

One of the key components of our study relates to the effective communication of health risks associated with the pandemic. Several studies in the literature provide significant insights and contributions to this context. Vaughan and Tinker [17] discuss a Framework for communication preparedness and implementation that summarizes the key actions toward efficient communication of health-risk related messages to key populations. They elaborate this through 'Recommendations for Public Health Planners and Risk Managers to Enhance Health Risk Communication Preparedness for Vulnerable Populations'. This is a very interesting study that has a direct link to the core research objective of our approach. We are concerned to analyze how social media impact can enhance health-risk communication and promote significant related academic purposes on the core topic of higher education institutions' teaching and learning.

Hanson-Easey et al. [18] deployed a focus-group research approach to investigate how social capital has a positive impact on the communication of health risks. This approach has an input into our research methodology. The study of the impact of social media in higher education institutions needs to be enhanced by focus-group analysis, with groups formed of key higher education administrators capable of communicating specific aspects of the pandemic emergency strategy. Concerning the research agenda for such focus-group approach, Muniz-Rodriguez [19], in a systematic review of 44 research articles, analyzes how social media have been deployed in the management of natural disasters. The review reveals diverse contributions through social media to emergency plans and disaster management.

Akter and Wamba [20] contribute to the scientific discussion of disaster management by analyzing the potential of 'big data' and analytics. Their study analyzes numerous works and concludes that 'big data' methods, such as visualizations, can promote the efficiency of disaster management plans. In our research, we take into consideration the potential of 'big data' and analytics research and deploy the data available through the sophisticated the KAU Web Observatory platform, which monitors social media contributions in the academic institution under study.

In our approach, the integration of previous ideas contributes further insights into the methodological framework depicted in Section 2.1 (Figure 1). Thus, our research targets the following areas:

- The understanding of perceptions of members of a focus group consisting of key stakeholders and academic decision-makers at KAU.

- The analysis of sophisticated big data and data-mining platforms capable of providing a realtime overview of the interactions of target users, with specific communication messages for the pandemic emergency.

- The construction of a methodological framework, with pillars relating to social media use and impact, as well as an institutional strategy for a pandemic emergency.

In Table 2, below, we summarize the key aspects of our selective literature review of contributions to social media research into efficient pandemic emergency management. We studied various works, but the chosen articles represent the focus of our study and contribute significantly to our research problem. 
Table 2. Overview of literature review for the pandemic emergency communication and social media.

\begin{tabular}{|c|c|c|c|}
\hline & \multicolumn{3}{|c|}{ Literature Review } \\
\hline Authors & Title of Article & Key Contribution & $\begin{array}{c}\text { Impact on Our Research } \\
\text { Model }\end{array}$ \\
\hline $\begin{array}{l}\text { Vaughan, } \\
\text { and Tinker } \\
(2009)\end{array}$ & $\begin{array}{l}\text { Effective Health Risk } \\
\text { Communication } \\
\text { About Pandemic } \\
\text { Influenza for } \\
\text { Vulnerable } \\
\text { Populations } \\
\end{array}$ & $\begin{array}{l}\text { The authors discuss the challenges of } \\
\text { health-risk communication and } \\
\text { introduce a thorough Framework for } \\
\text { Communication Preparedness } \\
\text { and Implementation. }\end{array}$ & $\begin{array}{l}\text { One of the key priorities in our } \\
\text { research is to construct an } \\
\text { integrated framework for } \\
\text { social media's impact on } \\
\text { communication in a } \\
\text { pandemic emergency. }\end{array}$ \\
\hline $\begin{array}{l}\text { Hanson-Easey et al. } \\
\text { (2017) }\end{array}$ & $\begin{array}{l}\text { Risk communication } \\
\text { for new and } \\
\text { emerging } \\
\text { communities: The } \\
\text { contingent role of } \\
\text { social capital }\end{array}$ & $\begin{array}{l}\text { In this study, the authors discuss the } \\
\text { role of social connectedness, or 'social } \\
\text { capital', in mediating the dissemination } \\
\text { and interpretation of natural hazard risk } \\
\text { information for new migrant } \\
\text { communities in South Australia. One of } \\
\text { the key aspects of their approach is the } \\
\text { deployment of a focus group. }\end{array}$ & $\begin{array}{l}\text { The deployment of a focus } \\
\text { group in our research study } \\
\text { will enhance the } \\
\text { understanding of perceptions } \\
\text { and actions of higher } \\
\text { education administrators } \\
\text { toward effective } \\
\text { communication of a } \\
\text { pandemic emergency. }\end{array}$ \\
\hline $\begin{array}{l}\text { Muniz-Rodriguez } \\
\text { (2020) }\end{array}$ & $\begin{array}{c}\text { Social Media Use in } \\
\text { Emergency Response } \\
\text { to Natural Disasters: } \\
\text { A Systematic Review } \\
\text { With a Public } \\
\text { Health Perspective }\end{array}$ & $\begin{array}{l}\text { Authors analyzed } 44 \text { research articles } \\
\text { related to the contribution of social } \\
\text { media in the emergency response to } \\
\text { natural disaster. This systematic review } \\
\text { provides interesting insights for the } \\
\text { deployment of social media for } \\
\text { public health. }\end{array}$ & $\begin{array}{l}\text { In our research model, } \\
\text { we need to integrate } \\
\text { benchmarks related to the use } \\
\text { of social media for } \\
\text { emergency response. }\end{array}$ \\
\hline $\begin{array}{c}\text { Akter and } \\
\text { Wamba (2017) }\end{array}$ & $\begin{array}{l}\text { Big Data and Disaster } \\
\text { Management: A } \\
\text { Systematic Review } \\
\text { and Agenda for } \\
\text { Future Research }\end{array}$ & $\begin{array}{l}\text { The authors discuss the contribution of } \\
\text { novel data-mining techniques to } \\
\text { disaster management and emphasize } \\
\text { the significance of visualization. }\end{array}$ & $\begin{array}{l}\text { It is critical to our approach to } \\
\text { investigate how advanced 'big } \\
\text { data' and data-mining } \\
\text { methods for social media data } \\
\text { can enhance decision-making } \\
\text { capabilities in } \\
\text { higher education. }\end{array}$ \\
\hline
\end{tabular}

\section{Research Methodology}

For the purpose of this study, we adopted a mixed-methods research approach in three integrated areas:

- Quantitative analysis of social media (Twitter) content: statistical analysis of social media content related to tweets belonging to all KAU university official accounts. These accounts are associated with various entities of the University, such as colleges, deanships, hospital, departments, and centers.

- Qualitative method: we interviewed the seven individuals responsible for managing KAU's most active official Twitter accounts in terms of number of Twitter posts and replies to users.

- Quantitative method: we designed an online survey consisting of 15 research questions/items, targeting the managers of KAU's 51 official Twitter accounts.

\section{Research Model and Objectives}

In our research model (Figure 2) there are six integrated components. The study of social media's impact in a pandemic emergency is organized around five complementary research objectives: 


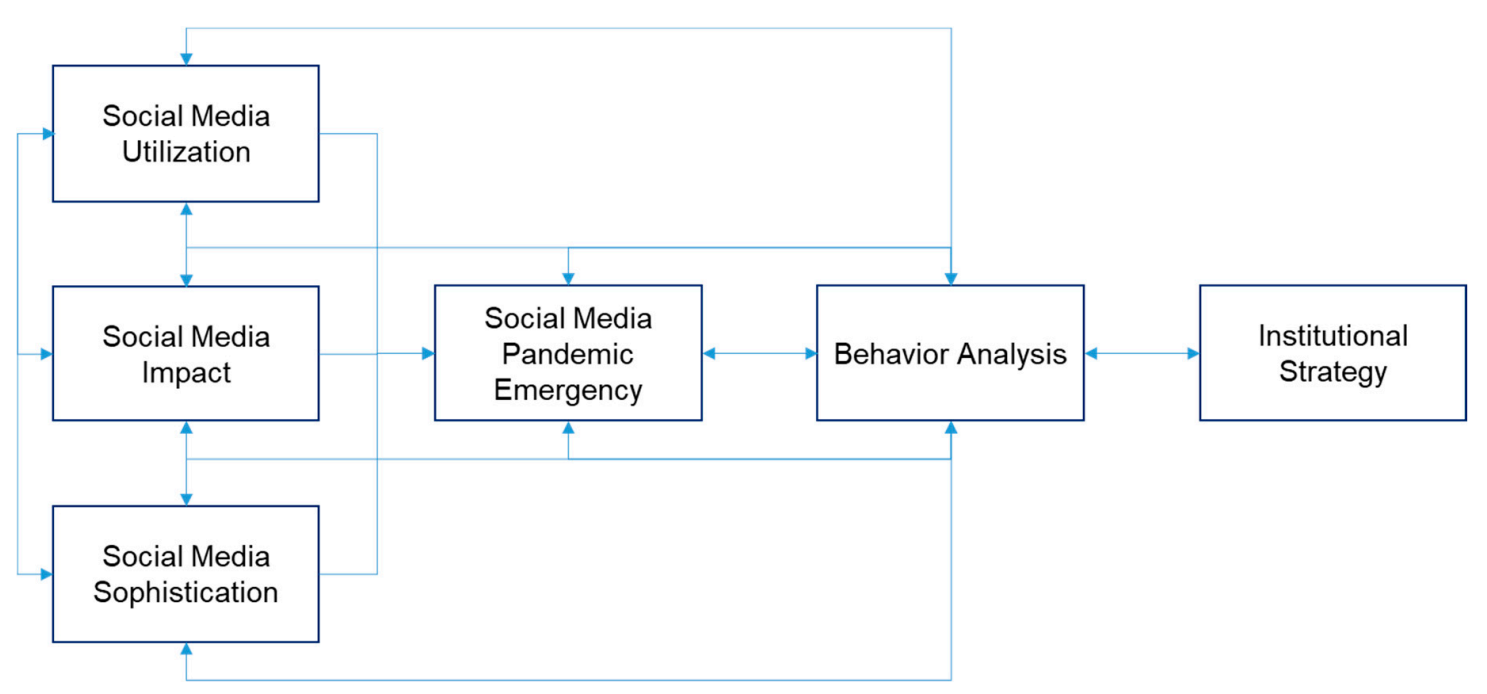

Figure 2. The research model.

- Research Objective 1: social media utilization. The main challenge here is to use statistical data available through the institution's web platforms in order to understand how KAU uses Twitter to deal with the pandemic. Another critical aspect of this objective is to provide the rationale behind the decision to use Twitter as a communication channel for the response to the pandemic.

- Research Objective 2: social media impact. It is important to understand the impact of KAU's social media strategy for the effective management of the pandemic emergency and for the establishment of effective communication. Furthermore, the measurement of the impact is related to the understanding of how social media helps an academic institution to adopt a fast-switch strategy, from offline to online learning and teaching. The ultimate dimension of this research objective concerns the impact of social media on effective communication in a pandemic.

- Research Objective 3: social media sophistication. The use of Twitter as a communication channel for a pandemic emergency plan requires a better understanding of technical matters concerning its efficiency. An analysis of how KAU adopted social media to communicate to the crowd and which key messages were selected for the campaign are the critical aspects under investigation in this study. Complementary aspects of this research objective are technical issues, such as the best strategy to answer questions when there are massive numbers of Twitter replies, and which Twitter service is the most effective to communicate during a pandemic.

- Research Objective 4: institutional strategy. Social media adoption is analyzed through the lenses of institutional strategy and of critical organizational resource. We intend to study how social media in times of pandemic can serve as key institutional best practice. Relevant questions on this research objective concern issues such as the mid-term plan for the social media strategy of the pandemic following a lockdown, and the key components of a campaign for effective institutional communication in a pandemic.

- Research Objective 5: behavior analysis. Social media are capable of advanced data- mining services, including text mining and sentiment analysis. In our study, we intend to provide an initial understanding of issues relating to user satisfaction, the sentiments of social media users relating to the pandemic emergency and the institution's capacity to serve efficiently the various stakeholders, including students, staff, and higher education administrators.

\section{Analysis and Main Findings}

In this section, we provide the initial analysis of our data, taking the research approach described in previous sections. First, we present the quantitative statistical analysis of the data resident on 
KAU's social media administration platform. Next, we analyze the key findings of the qualitative and quantitative methods.

\subsection{Quantitative Analysis of Social Media (Twitter) Content}

For this study, we collected Twitter data from all tweets by KAU official accounts between 1 January and 31 March, 2020. The analysis involves 8200 tweets. The accounts are associated with various KAU entities, such as colleges, deanships, hospitals, departments, and centers. In the following sub-section, we show the number of tweets over the period for all accounts and the group of main accounts to find out the change in Twitter usage. Moreover, we show the main hashtags associated with the collected tweets.

\subsubsection{Quantitative Analysis of Twitter Content: All KAU Accounts}

In Figure 3, below, we summarize the content delivery in the official Twitter accounts at KAU. There is an impressive increase in posts by all authors.

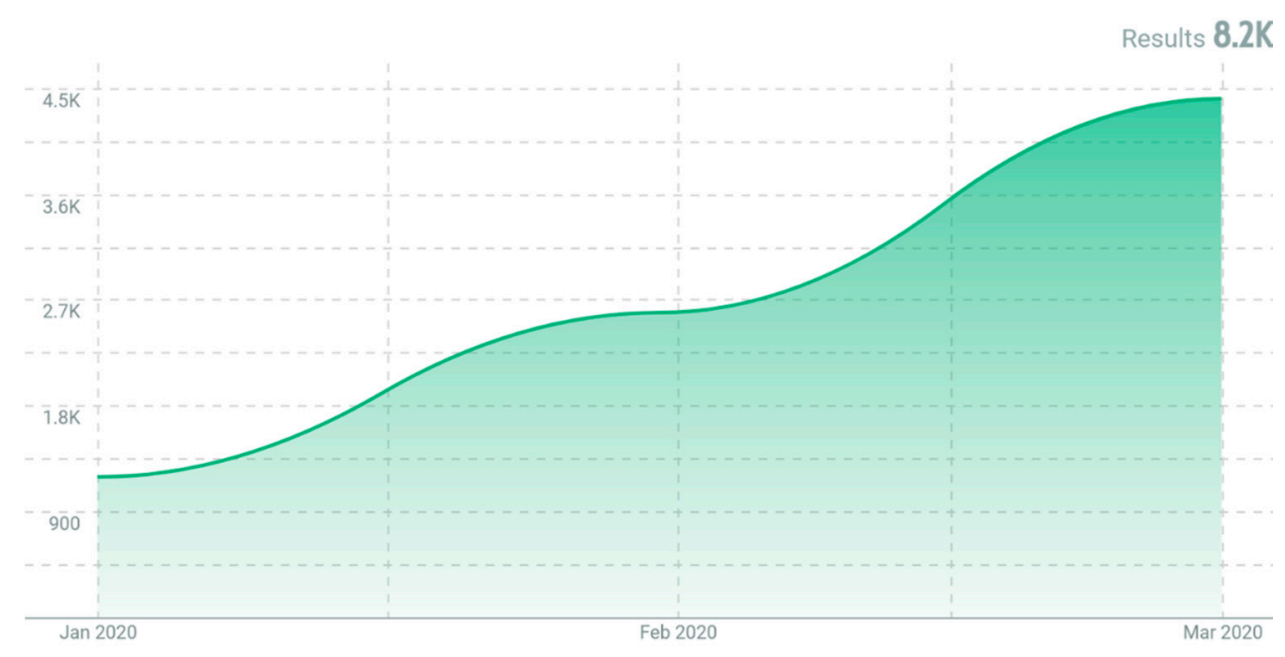

Figure 3. Twitter posts by King Abdulaziz University (KAU) official accounts.

In Figure 3, we depict an impressive finding about the deployment of Twitter at KAU: 8200 tweets, in total, were posted in the three-month period from 1 January to 31 March, 2020. This is a sharp increase in the number of tweets posted by all KAU Twitter accounts, representing a $245 \%$ increase over the relevant previous period. This trend shows the extensive deployment of Twitter in KAU in this pandemic period and prompts questions about the key messages that were communicated in alignment with key institutional strategies. This issue will be answered both qualitatively and quantitatively in the following sections.

\subsubsection{Quantitative Analysis of Twitter: Main Accounts}

In our study, we analyzed separately the Twitter accounts of the five entities expected to be most heavily involved during the pandemic to find out whether there was any abnormal increase in their Twitter usage. These accounts are as follows:

- Deanship of Admission \& Registration

- Deanship of e-Learning and Distance Education

- Deanship of Students' Affairs

- KAU Hospital

- Health Promotion Center 
Figures $4-8$ below give an overview of the evolution over time of the tweets by these entities. It is evident from the graphical patterns that the deanships and centers under study followed a fairly similar strategy. There was an incremental deployment of Twitter for the communication and distribution of knowledge and information on the pandemic emergency.

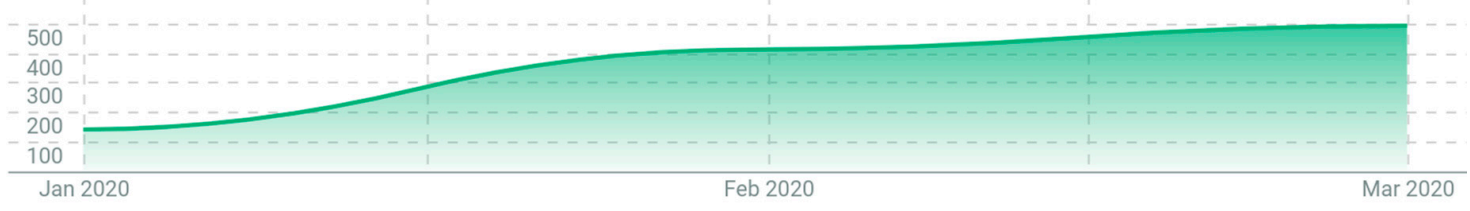

Figure 4. Tweets' evolution over time for Deanship of Admission \& Registration.

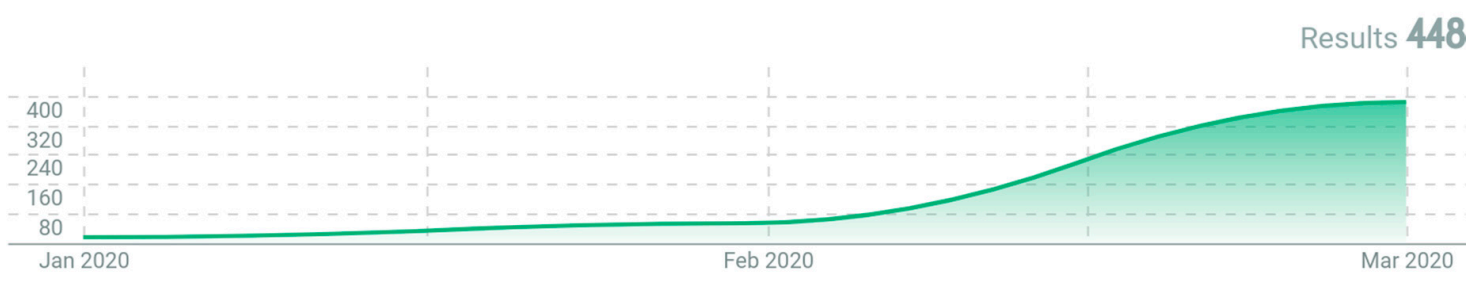

Figure 5. Tweets' evolution over time for Deanship of e-Learning and Distance Education.

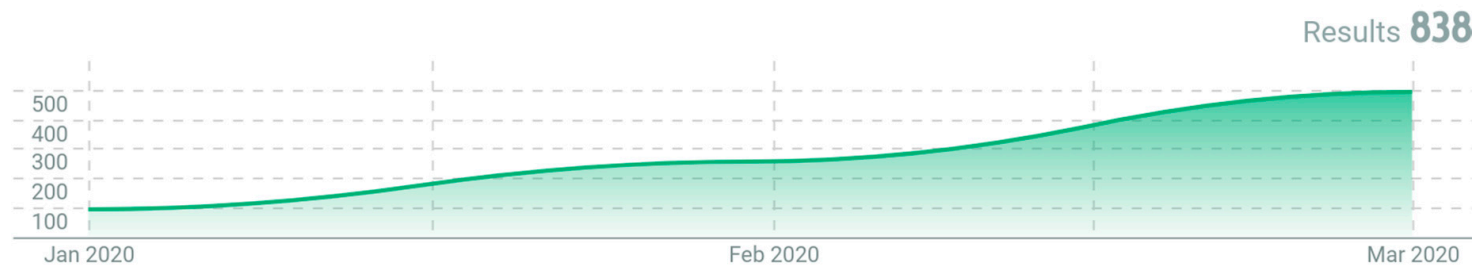

Figure 6. Tweets' evolution over time for Deanship of Students' Affairs.

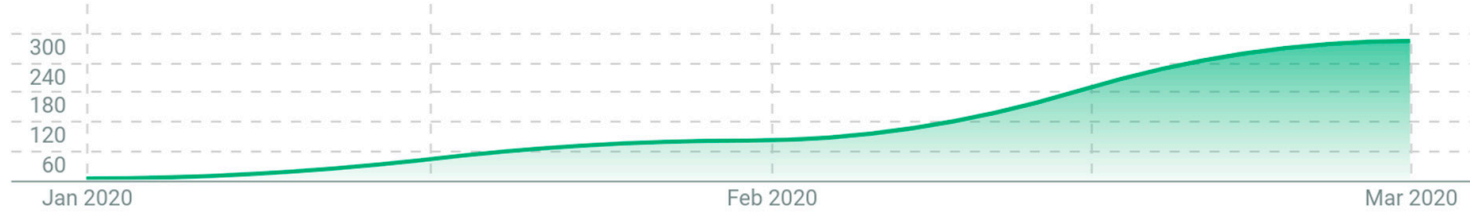

Figure 7. Tweets' evolution over time for KAU Hospital.

Figure 7. Tweets' evolution over time for KAU Hospital.

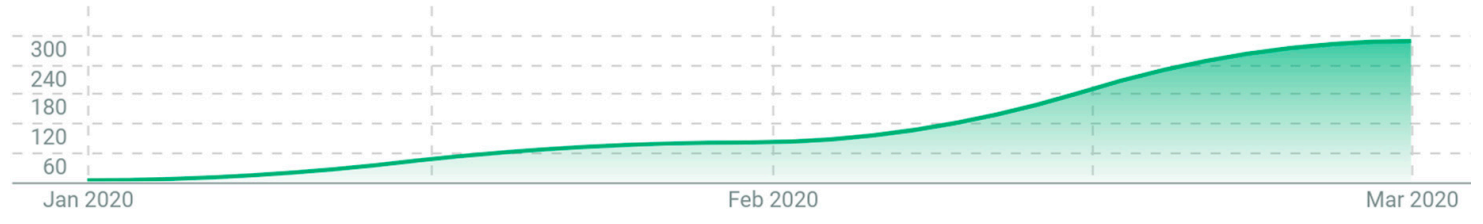

Figure 8. Tweets' evolution over time for KAU Health Promotion deanship.

\subsubsection{Quantitative Analysis of Twitter: Number of Replies}

An initial interpretation of these data is that social media, and especially Twitter, were deployed at KAU as a key communication channel in the pandemic emergency. The analysis of the collected 
tweets from all KAU accounts shows that the KAU account managers replied to 1900 queries from the crowd. This vast number (Figure 9) indicates a systematic approach by KAU's administration to provide timely, accurate, and efficient communication, allowing interaction with the targeted users.

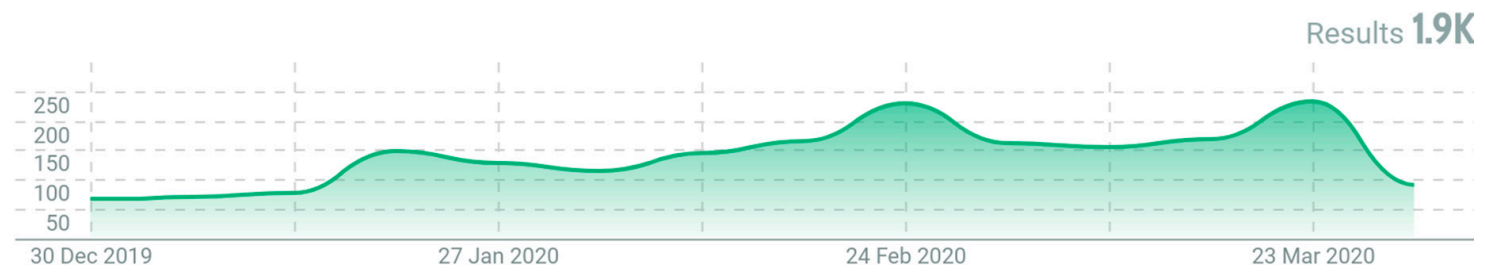

Figure 9. Number of replies to people by all University accounts.

\subsubsection{Quantitative Analysis of Twitter: Hashtag Cloud}

One of the most interesting findings on the application of text mining relates to the key topic of tweets' messages, replies, and discussions. Figure 10, below, gives a summary of the top hashtags during the pandemic period, translated from Arabic to English for the purpose of this study. As expected, a key component of all tweets is hashtags that include COVID-19:

- \#New Corona_Virus

- \#Corona_Virus_Covid19

- \#We are all responsible

- \#Prevention

- \#The scientific endowment

- \#Stay in the house

- \#Saudi Ministry of Health

- \#Deanship of Student Affairs

- \#World Health Organization

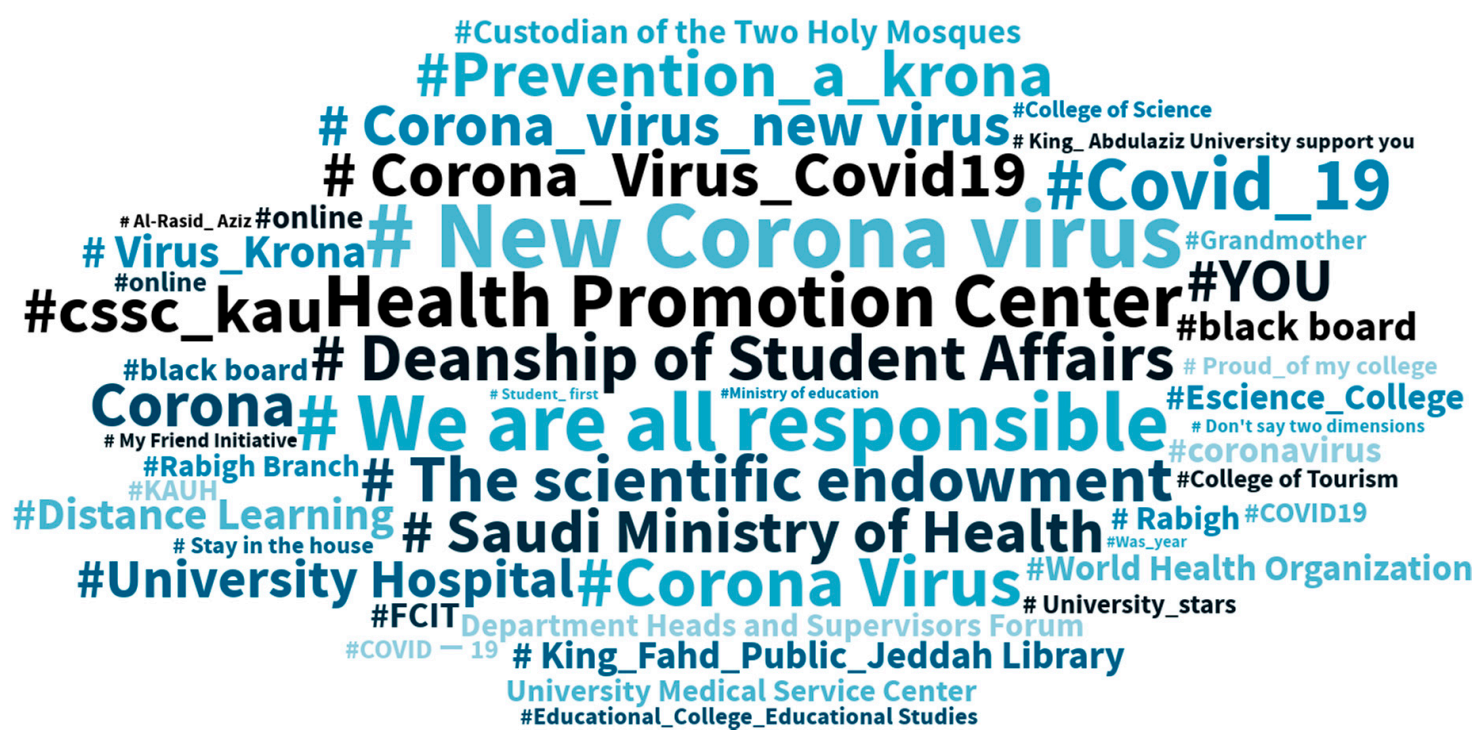

Figure 10. Twitter themes and hashtags of university accounts.

4.1.5. Discussion of the Quantitative Analysis of Social Media (Twitter) Content

This preliminary statistical analysis of key data from the Social Media Center in KAU highlights four significant findings: 
1. KAU adopted Twitter as a key communication channel, with an impressive increase in content dissemination and awareness during the pandemic emergency.

2. The main conclusion of this preliminary analysis of Twitter data is that KAU moved fast to adopt Twitter as a trusted means of communication for the design and implementation of an institutional strategy, aiming to disseminate fast, accurate and up-to-date knowledge on the pandemic with a wide reach of targeted users. All the centers and deanships included in this research followed a similar evolution of knowledge and awareness dissemination in their tweets. The adoption of Twitter by the KAU Distance Learning Center to communicate critical policy-making and teaching and learning-related facts and developments is impressive.

3. Over the same period, a significant increase was reported in the interactions and replies of KAU users, mostly from all centers and deanships.

4. Sentiment analysis shows a significant evolution in neutral and positive sentiments during this period.

5. Last, but not least, the hashtags adopted in most tweets are closely related to the pandemic emergency and the new strategies launched by the KAU.

In the next section, on qualitative analysis, it is important to understand how social media helped KAU to promote the flexibility and sustainability of education and learning over time.

In the second section of our analysis, in which we present the key findings of the qualitative research through the focus-group study, additional insights will be provided by the key stakeholders and administrators.

\subsection{Qualitative Method}

This section aims to provide further understanding on how Twitter was used to deal with the pandemic. In other word, we investigate why the use of almost all KAU's Twitter accounts increased significantly. Therefore, a qualitative method [21] is used in this research through semi-structured interviews containing the main question: how do you utilize Twitter to deal with the pandemic emergency?

We interviewed the seven individuals, three males and four females, responsible for managing KAU's most active Twitter accounts in terms of numbers of Twitter posts and replies to the crowd. The representatives of active KAU Twitter accounts are associated with centers such as the Deanship of Student Affairs, the Health Promotion Center, the Clinical Skills and Simulation Center, the Faculty of Human Science and Design and the KAU Media Center.

We approached the participants personally and asked them to provide written feedback, and then this was combined and thematically analyzed. It resulted in three main themes on the usage of Twitter during the pandemic: administrative purposes, education sustainability, and community responsibility. These themes show how Twitter was used purposefully during the pandemic. We discuss the results of each theme in the following sub-sections.

\subsubsection{Administrative Purpose}

Twitter was used to announce the new regulations from the Ministry of Education and KAU effectively (see Table 3 below). The published rules explain the reasons for the shift to online-based education and grade distribution and the approved online assessment tools. The number of interactions between these accounts and students was massive. Students asked for further explanations, enquired about issues such as the KAU banking services for students, the supply of free laptops for those in need to undertake online learning and the technical issues that they encountered on the online platform, and raised questions about administrative regulations. 
Table 3. Twitter's effectiveness for administrative purposes in KAU.

\begin{tabular}{|c|c|c|}
\hline Administrative Purpose & Effective & Student Response \\
\hline $\begin{array}{l}\text { Communication of regulations from } \\
\text { Ministry of Education and KAU }\end{array}$ & Yes & $\begin{array}{c}\text { More questions, e.g., KAU banking services } \\
\text { for students }\end{array}$ \\
\hline Rules for shifting to online education & Yes & Enquiries for free laptops to undertake online training \\
\hline Grade distribution & Yes & Technical questions \\
\hline Approved online assessment tools & Yes & Technical questions \\
\hline
\end{tabular}

\subsubsection{Educational Sustainability}

Based on qualitative analysis of the focus group, Twitter was used heavily for various duties to sustain educational processes during the COVID-19 pandemic (see Table 4). To engage researchers in these activities, it was used to announce the decision to conduct student defense of master's and doctoral qualifications online. In addition, it was used to announce student awards for online competitions. Since tuition shifted to online, short courses were provided on using Blackboard and online meeting platforms. Twitter helped to provide both online academic advice and psychological counseling. KAU used Twitter to send spiritual, reassuring, and encouraging messages to students to help them to feel positive and to overcome the side effects of the pandemic. In addition, Twitter disseminated information relating to disabled students and students with autism, who were provided with specialized online courses to keep them engaged in the academic environment during the COVID-19 pandemic.

Table 4. Twitter's effectiveness for educational sustainability.

\begin{tabular}{ccc}
\hline Educational Sustainability (Twitter Used to Communicate) & Effective & Student Response \\
\hline Online defense for master's and doctoral students & Yes & Positive reaction \\
\hline Student award announcements for various online competitions & Yes & Positive reaction \\
\hline $\begin{array}{c}\text { Online short courses on using Blackboard and online meeting platforms } \\
\text { encouraging messages to students, helping them to be positive and to } \\
\text { overcome the side effects of the pandemic }\end{array}$ & Yes & Positive reaction \\
\hline $\begin{array}{c}\text { Disabled students and students with autism were provided with } \\
\text { specialized online courses to keep them engaged in the academic } \\
\text { environment during COVID-19 pandemic }\end{array}$ & Yes & Positive reaction \\
\hline $\begin{array}{c}\text { Academic advice and psychological counseling } \\
\text { Acandive reaction }\end{array}$ & Yes & Positive reaction \\
\hline
\end{tabular}

\subsubsection{Community Responsibility}

Twitter helped KAU to perform its community responsibility duties during the COVID-19 pandemic (see Table 5). It was used to educate the community about COVID-19 and disseminate safety tips via moving graphics and infographics and online workshops in nine languages. It provided ideas for home-based activities during social distancing. Twitter also helped to respond to questions about healthcare during the pandemic.

Table 5. Twitter's effectiveness for community responsibility.

\begin{tabular}{ccc}
\hline Education Sustainability (Twitter Used to:) & Effective & Student Response \\
\hline $\begin{array}{c}\text { Educate the community about COVID-19 and safety tips via moving } \\
\text { graphic and infographics and online workshops in nine languages }\end{array}$ & Yes & Positive reaction \\
\hline Provide ideas for home-based activities during social distancing & Yes & Positive reaction \\
\hline Respond to questions about healthcare during the COVID-19 pandemic & Yes & Positive reaction \\
\hline
\end{tabular}




\subsection{Quantitative Method}

The quantitative method was used in this study purposefully, to provide factual evidence on how Twitter was used during the pandemic. We designed a questionnaire with 15 questions, each with a five-point Likert-type scale ranging from strongly disagree to strongly agree, with a neutral midpoint. We distributed the questionnaire to all 51 official Twitter account managers at KAU, and 19 of them (10 males and nine females) responded to the questionnaire. We used Cronbach's Alpha to test its reliability, and the results show that the questionnaire is indeed reliable, as Cronbach's Alpha value is 0.907 .

For the purpose of this research, we used the mean value of each question's responses to measure the agreement or disagreement of participants with the statements. The results show that the overall mean value of all questions is 3.38, out of four, which shows that most responses were on the agreement side, which represents the positive role that the use of Twitter played during the pandemic.

For each question, a Likert scale was used to indicate a positive perception of the effectiveness of Twitter to promote the objectives of an institutional wide social media strategy (see Table 6).

The items with the strongest values relate to:

- The strategic use of Twitter for the social media campaign during the COVID-19 pandemic $($ mean $=3.74)$.

- The capacity of Twitter to reach students immediately during the COVID-19 pandemic $($ mean $=3.53)$.

- The realization of a greater social media activity during the COVID-19 pandemic ( mean $=3.47$ ).

- The efficiency of information provided on Twitter by KAU accounts to facilitate the switch to online learning at KAU during the COVID-19 pandemic (mean $=3.47$ ).

- The effectiveness of Twitter as a tool for mass communication (including messages and reply) during the COVID-19 pandemic (mean $=3.47$ ).

- The perceptions of users that KAU used Twitter effectively during the COVID-19 pandemic $($ mean $=3.47)$.

- The ease of Twitter to support users to respond effectively to questions and comments (mean =3.42).

- The preference for using Twitter over official communication channels during the COVID-19 pandemic $($ mean $=3.42)$.

Moreover, from the same analysis of items, additional bold findings are summarized here as follows:

- Twitter helps communication between KAU students, faculty and administrators during the COVID-19 pandemic (mean $=3.37)$.

- We try to reply to all questions received on Twitter during the COVID-19 pandemic (mean = 3.37).

- Using Twitter should be adopted in the emergency plan during the COVID-19 pandemic (mean $=3.32$ ).

- Twitter helps to reduce academic challenges to online learning during the COVID-19 pandemic $($ mean $=3.26)$.

- We are satisfied with using Twitter for educational purposes during the COVID-19 pandemic ( mean $=3.26$ ).

- Twitter helps to reduce technical challenges to online learning during the COVID-19 pandemic (mean $=3.21)$. 
Table 6. Item statistics for our survey of official KAU Twitter accounts.

\begin{tabular}{|c|c|}
\hline Item Statistics & Mean \\
\hline Our Twitter account is more active during the COVID-19 pandemic & 3.47 \\
\hline You receive more questions regarding education and the COVID-19 pandemic & 2.95 \\
\hline You respond effectively to questions and comments & 3.42 \\
\hline Twitter helps to reach students immediately during the COVID-19 pandemic & 3.53 \\
\hline We use Twitter for social media campaign during the COVID-19 pandemic & 3.74 \\
\hline $\begin{array}{l}\text { Information provided on Twitter by KAU accounts facilitated switching to online learning at KAU } \\
\text { during the COVID-19 pandemic }\end{array}$ & 3.47 \\
\hline Twitter helps to reduce academic challenges to online learning during the COVID-19 pandemic & 3.26 \\
\hline $\begin{array}{l}\text { Twitter helps communication between KAU students, faculty and administrators during the } \\
\text { COVID-19 pandemic }\end{array}$ & 3.37 \\
\hline Twitter helps to reduce technical challenges to online learning during the COVID-19 pandemic & 3.21 \\
\hline $\begin{array}{l}\text { Twitter is an effective tool for mass communication (including messages and replies) in the } \\
\text { COVID-19 pandemic }\end{array}$ & 3.47 \\
\hline We try to reply to all questions received on Twitter during the COVID-19 pandemic & 3.37 \\
\hline We prefer using Twitter to the official communication channels during the COVID-19 pandemic & 3.42 \\
\hline Using Twitter should be adopted in the emergency plan during the COVID-19 pandemic & 3.32 \\
\hline We are satisfied with using Twitter for educational purposes during the COVID-19 pandemic & 3.26 \\
\hline KAU used Twitter effectively during the COVID-19 pandemic & 3.47 \\
\hline
\end{tabular}

\section{Discussion}

\subsection{Research Objectives 1, 2, and 3: Social Media Sophistication Utilization and Impact}

In Figure 11 below, we provide an overview of the qualitative perception of focus-group member responses on the positive contribution of Twitter during the COVID-19 pandemic emergency. It is evident that the use of Twitter contributed significantly in five ways:

- Administrative resilience: KAU adopted Twitter in order to communicate novel, flexible, and trusted procedures relating to the shift of education and training to online, as well as trusted content from key stakeholders' accounts.

- Education sustainability: Twitter permitted the implementation of an effective communication strategy of flexible, novel processes for the sustainable delivery of promised value in the education process. This is a significant institutional gain for KAU that has great potential for the recovery period following the pandemic.

- Community responsibility was built on the transparency and trust of the Twitter strategy. The messages about staying safe at home and continuing to be productive and efficient during the pandemic emergency helped to maintain positive attitudes across the KAU community.

- Another positive impact of Twitter use at KAU relates to the community bond. Providing ubiquitous, flexible communication, a community bond and positive messages to students achieved a feeling of belonging to an institution that cares about its delivery of promised value. 


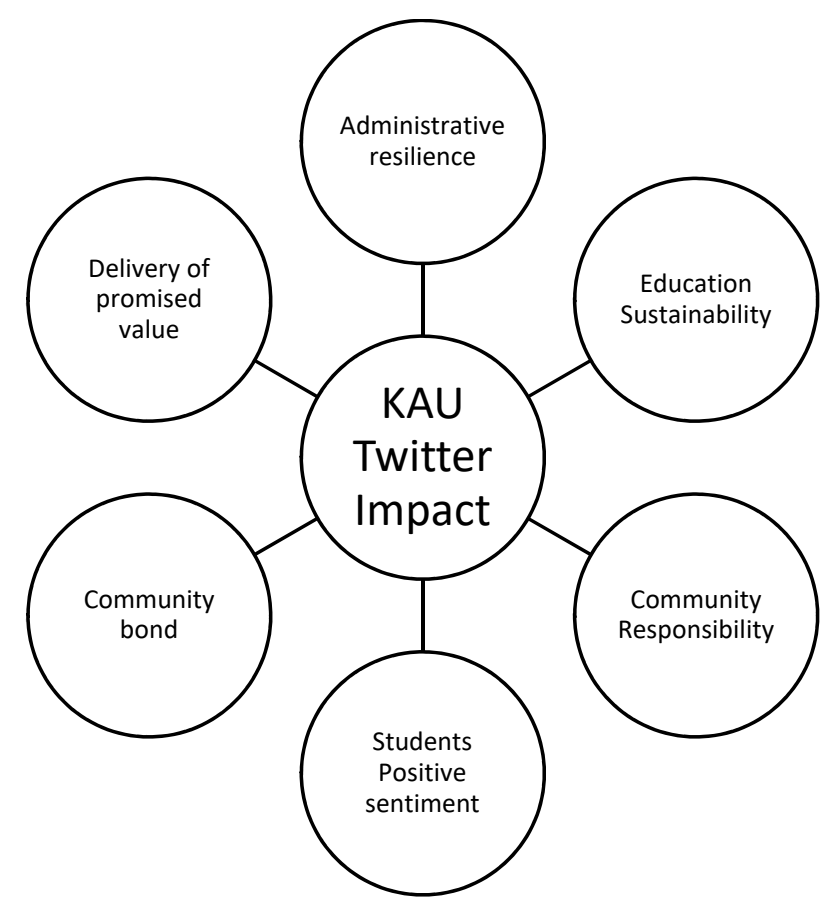

Figure 11. Twitter impact, as per qualitative focus-group analysis.

\subsection{Research Objectives 4 and 5: Behavior Management and Institutional Strategy}

One of the main intellectual contributions of our study is associated with its methodological framework, which can be used as an international benchmark for the strategic impact of social media toward pandemic management in higher education institutions. In fact, the qualitative and quantitative research presented in previous sections provides interesting insights into the effective use of Twitter as a communication vehicle with a significant impact in higher education institutions at a time of pandemic. Five complementary pillars provide a synergetic framework for the establishment of effective mechanisms in such times. We provide below a brief overview:

- Social media governance: a key component of our framework relates to the governance of social media within academic institutions, universities, and colleges. In KAU, the presence of the social media center known as KAU Web Observatory for Web Studies permitted both the implementation and execution of effective Twitter strategies and an alignment of social media communication and institutional strategies. In the context of the COVID-19 pandemic, this was a critical success factor that proved the readiness of KAU to promote efficiently the rapid changes to institutional polices. A well-documented code of ethics for social media communications is a prerequisite for the strategic impact of social media, together with trust mechanisms for content authors and the content's creation, syndication and dissemination.

- Social media resilience: as explained in previous sections, the three critical aspect of social media's impact and resilience are administrative resilience, educational sustainability, and community responsibility. Furthermore, the promotion of positive sentiment, the delivery of promised value and the community bond are critical aspects of social media's impact and resilience. Twitter proved to be a key enabler in KAU toward this critical milestone.

- Social media utilization: as a technical approach about social media use with relevance to the literature, KAU adopted Twitter as a dialogic communication channel and secured valuable communication by deploying trusted sources and content from external stakeholders. Thus, the deployment of Twitter promoted the institutional brand and supported positive perceptions about the capacity of the institution to manage the pandemic emergency. 
- Decision-making capability: in our methodological framework, social media impact needs to be anchored in an institution-wide enhanced decision-making capability at higher education administration level. This includes integrated 'big data' and analytics, the Social Media Observatory, sophisticated key performance indicators, and studies of economic sustainability related to the new post-pandemic emergency environment. This is a key aspect of our future research.

- Institutional strategy: the integral institutional strategy of social media impact in pandemic emergency demands the orchestration of five components: governance of the pandemic emergency, a communication strategy, a shift to an online context, and sustainability and economic feasibility.

\section{KAU Pandemic Framework}

Our key contribution, the KAU Pandemic Framework, is summarized in Figure 12. The framework integrates the significant contributions from the critical review and from the combined research methods applied in this study. It is a framework for social pandemic management through social media and can be used by higher education administration as an advanced decision-making framework. It can serve as a strategic management tool in universities and colleges to design and implement campaigns for the social management of a pandemic. As analyzed in Section 5.2 above, the five synergetic pillars constitute an integrated framework:

- Social media governance: in a higher education institution, it is critical to justify, promote, and implement an integrated social media governance strategy. There are several key requirements, relating especially to data protection, privacy, collection, and processing for meaningful academic purposes. Additionally, governance of social media enables the consideration of microcontent and social communications as a critical managerial asset for university and college purposes.

- Social media resilience: social media resilience is a concept that is introduced by our framework. Flexibility and continuity of value delivery in the context of higher education institutions require new perceptions of resilience regarding the academic objectives, sustainability, and development. It is also about achieving a feeling of belonging in an organization that has the capacity to adapt to emerging events and pandemics.

- Social media utilization: a core part of our framework is related to the sophistication of social media platforms and data-processing capabilities.

- Decision-making capability: in our methodological framework, the social pandemic framework is oriented to decision-making. It is not only a framework for describing the current status in pandemic management but is integrated with advanced decision-making capabilities. In the abstract-level presentation in Figure 12, the core components of the various subsidiary aspects of the decision-making capability are not analyzed in any further detail. This is the aim of a future publication on the use of the framework for decision-making and control.

- Institutional strategy: in our social pandemic framework, the component of institutional strategy institutionalizes all the activities associated with pandemic management and provides the core strategies that are to be distributed across and beyond all aspects of the framework.

The implications of using this framework are yet to be realized, but the following are some possible implications:

- It provides a high-level strategic model for the management of social media impact and pandemic emergency management in universities and colleges.

- It can be used as a strategic decision-making tool for the analysis of gaps and inefficiencies of the social media plans deployed and the challenges to pandemic management.

- It sets a concrete 'big data' and analytics framework for the specification of particular metrics and key performance indicators for measuring the impact of social media in universities.

- It integrates social and technological aspects in a manner that permits the enhancement of higher education's sustainability and resilience. 
- It is directly linked to future sustainability and economic feasibility studies for the transition of education from face-to-face to online.

- It provides a methodological approach to higher education administrators of proactive actions for the management of future pandemic emergencies.

- It justifies value delivery on the basis of detailed empirical data and it is tested with data and methods from a well-established leading academic university, KAU.

- It proves that the integration of social media governance in higher education institutions leverages their capacity to deal effectively with unforeseen, situations.

- It initiates scientific discussion on the impact of social media on the efficiency of modern academic institutions [22].

- It can serve as a first step toward standardization of social media's impact in universities.
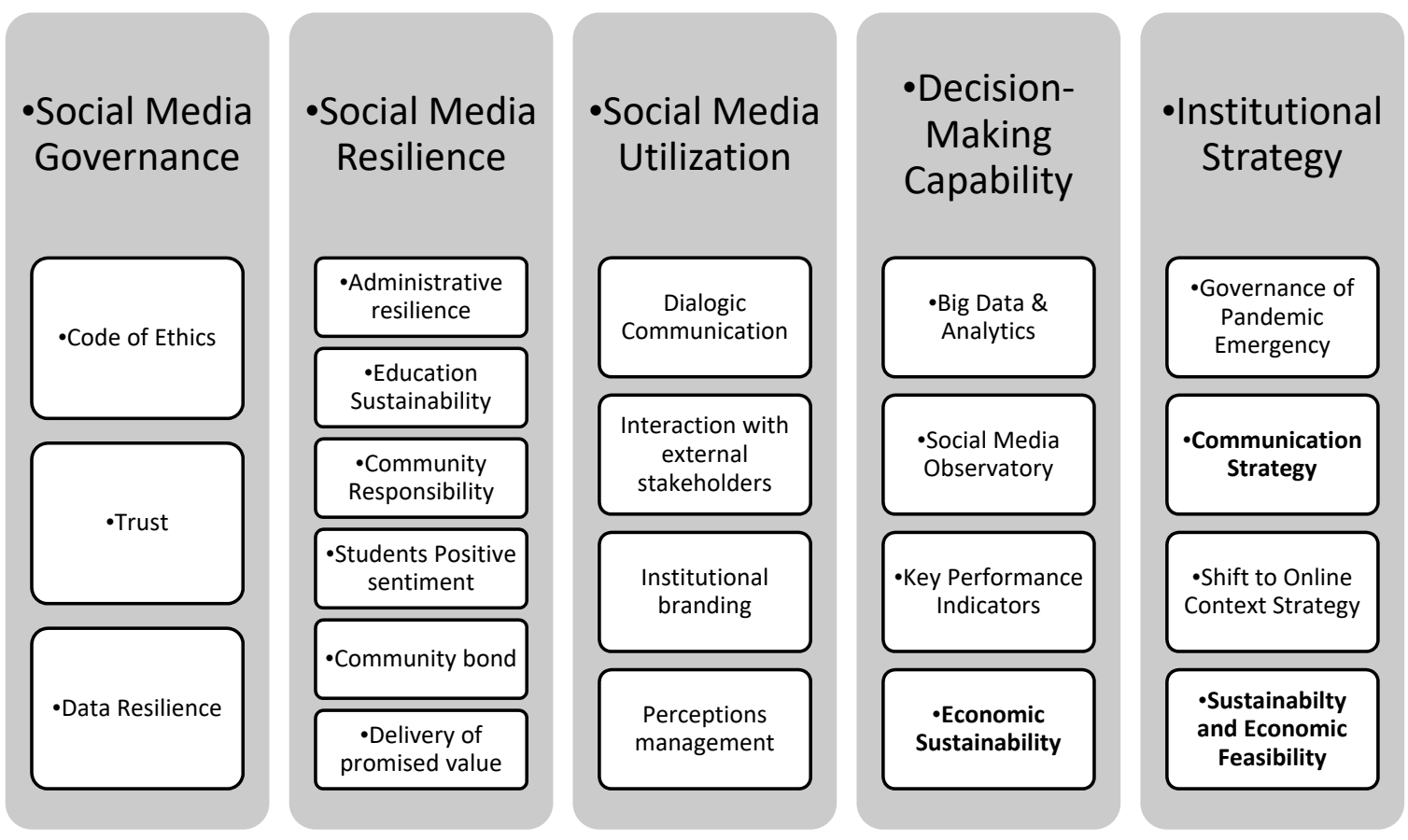

Figure 12. KAU Pandemic Framework: a benchmark for the strategic impact of social media toward pandemic management in higher education institutions.

The KAU Pandemic Framework can be a reference decision-making tool for different types of stakeholders. For higher education administrators provides a holistic, high-level, abstract, strategic tool for designing, implementing, monitoring and adjusting social media strategies for pandemic management. The philosophy also of the model can be adopted to other type of crisis that need to be handled at an institutional wide context. It incorporates significant institutional objectives and milestones that should be achieved through the orchestration of managerial capabilities. For faculty and teachers, provides a roadmap, for resolving issues and challenges, with the agreement of administration and with the provision of sustainable education and community responsibility. In this work we did not emphasized in the core aspect of delivering education in the context of pandemic since we run in parallel a complementary research especially focused on the transition from offline to online training. It is also a significant framework for students and trainees, since, offers a real time mechanism for the interpretation of student's perception for crisis and their support with trusted learning, content and community bond.

It is intended to provide a systematic tool for policymaking and crisis management in higher education institutions through strategic management of social media. We intend to enrich and to update further the KAU Pandemic Framework with emphasis on its decision-making capability. Our future 
research contribution will focus on the justification of a number of Key Performance Indicators for the measurement of the social media utilization and social media resilience towards the achievement of institutional objectives and milestones in the context of crisis.

One of the key characteristics of the framework is its flexibility and adoptability. It sets a unified framework for designing and implementing higher education administration strategies for social media and crisis management and at the same moment serve as a policy making master document. In the future, we intend to operationalize the five pillars of our framework with an integrated big data ecosystem for the measuring of the social media impact in times of crisis.

We have also to emphasize that COVID-19 pandemic was used as a case study, while the proposed framework can be used for the management of other types of crisis.

\section{Conclusions}

In this study, we introduced our proposed methodological framework, the KAU Pandemic Framework, to deal with the pandemic of COVID-19. The KAU Pandemic Framework integrates five pillars of strategic adoption of social media: social media governance; social media resilience; social media utilization; decision-making capability; and institutional strategy. Our research study can be used as a benchmark for relevant studies worldwide on the analysis of pandemic emergency management strategies in colleges and universities. Moreover, our methodological approach can be adopted for the delivery of similar methods in other institutions. Our three-tier, mixed-method research approach deploys statistical analysis of instructional social media data, together with interviews and a questionnaire that can be deployed as best practice.

In this complicated context of pandemic emergency communication and social media impact, to the best of our knowledge this study represents the first analysis of an ongoing research approach that will integrate more data and testing in future. Given the spread of COVID-19 worldwide, we are expecting a major increase in the body of scientific literature on this research domain and new insights from contributors all over the world.

The main limitation of our study is related to the analysis of KAU social media strategy for the pandemic management without analysis of worldwide benchmarks from other institutions. It is evident though that this is one of the first efforts worldwide to document, analyze, and justify the aspects of an integrated social media strategy in universities and colleges. This will be the objective of a newly undertaken research for the update of our framework with the analysis of data available from desktop research, as the relevant literature of the domain will grow over the next couple of years.

In our future research directions, we intend both to analyze in depth the key aspects of the institutional transition to online delivery by KAU and to understand the micro- and macro-economic implications. Finally, we intend to enrich our methodological framework with a novel set of 50 key performance indicators for pandemic management and social media impact for higher education institutions [23].

We need also to highlight some key conclusions out of this research related also to the critical literature review and research study we conducted. First, social media provides a flexible, autonomous, and direct way of online communication that permits the distribution of trusted content and guidelines for policy making [24]. One of the key conclusions is that social media governance is an integrative pillar of our framework. There are critical aspects of this governance that need further elaboration with key issues related to code of ethics, trust, and data resilience. This means that academic institutions should cultivate a transparent, ubiquitous social media governance across and within their contexts.

Another significant conclusion is that our framework enhances higher education decision- making capabilities. The integration of various pillars, and critical value adding components, highlights the need for total quality management over social media strategies. The contribution of our work is a first step towards the development of a sophisticated ecosystem for critical success factors, and key performance indicators for education and social media sustainability in times of pandemic. We also highlight that the lessons learnt through this process offer significant value for the post-COVID-19 
period, and make this research relevant in a greater and broader context: the case of the COVID-19 pandemic must be considered as a case study with global features for a variety of other kinds of crises. Thus, we do believe that the contribution of our work expands significantly the short and midterm of COVID-19 pandemic.

Another significant conclusion of our research is that crisis management in higher education is a bold response of university social responsibility (USR) principles [25]. The pandemic management and the strategic use of social media for this purpose, prove that universities serve their stakeholders according to social responsibility principles with main emphasis to be paid on the educational sustainability.

Finally, our research promotes key ideas for the role of education for sustainable development [26]. The cultivation of principles, decision support systems, and ecosystems of data analysis for responding to challenges during crisis must be understood as key aspects of higher education administration priorities [27]. Very shortly, we will also communicate the findings of our complementary research about the key issues of the transition of education in KAU from classroom-based to online. Then we will also update our framework presented in this study with a technology enhanced learning framework for education sustainability in times of pandemics.

Author Contributions: Writing—original draft A.O.A.-Y., A.A.-H., H.J.B., M.B., M.D.L., N.R.A. All authors have read and agreed to the published version of the manuscript.

Funding: The authors received no specific funding for this work.

Conflicts of Interest: The authors declare no conflict of interest.

\section{References}

1. Arafat, S.; Aljohani, N.R.; Abbasi, R.; Hussain, A.; Lytras, M. Connections between e-learning, web science, cognitive computation and social sensing, and their relevance to learning analytics: A preliminary study. Comput. Hum. Behav. 2019, 92, 478-486. [CrossRef]

2. Lytras, M.D.; Raghavan, V.; Damiani, E. Big data and data analytics research: From metaphors to value space for collective wisdom in human decision making and smart machines. Int. J. Semant. Web Inf. Syst. 2017, 13, 1-10. [CrossRef]

3. Lytras, M.; Aljohani, N.R.; Visvizi, A.; Ordonez De Pablos, P.; Gasevic, D. Advanced decision-making in higher education: Learning analytics research and key performance indicators. Behav. Inf. Technol. 2018, 37, 937-940. [CrossRef]

4. Visvizi, A.; Daniela, L.; Chen, C.W. Beyond the ICT- and sustainability hypes: A case for quality education. Comput. Hum. Behav. 2020. [CrossRef]

5. Visvizi, A.; Jussila, J.; Lytras, M.D.; Ijäs, M. Tweeting and mining OECD-related microcontent in the post-truth era: A cloudbased app. Comput. Hum. Behav. 2020. [CrossRef]

6. Alkmanash, E.H.; Jussila, J.J;; Lytras, M.D.; Visvizi, A. Annotation of Smart Cities Twitter Microcontents for Enhanced Citizen's Engagement. IEEE Access 2019. [CrossRef]

7. Mora-Cantallops, M.; Sánchez-Alonso, S.; Visvizi, A. The influence of external political events on social networks: The case of the Brexit Twitter Network. J. Ambient Intell. Humaniz. Comput. 2019. [CrossRef]

8. Aljohani, N.R.; Abbasi, R.A.; Bawakid, F.M.; Saleem, F.; Ullah, Z.; Daud, A.; Aslam, M.A.; Alowibdi, J.S.; Hassan, S. Web Observatory Insights: Past, Current, and Future. Int. J. Semant. Web Inf. Syst. 2019, 15, 52-68. [CrossRef]

9. Saeed, Z.; Abbasi, R.A.; Maqbool, O.; Sadaf, A.; Razzak, I.; Daud, A.; Aljohani, N.R.; Xu, G. What's Happening around the World? A Survey and Framework on Event Detection Techniques on Twitter. J Grid Comput. 2019, 17, 279-312. [CrossRef]

10. Aljohani, N.; Alahmari, S.; Aseere, A. An Organized Collaborative Work Using Twitter in Flood Disaster. In Proceedings of the ACM Web Science Conference 2011, Koblenz, Germany, 14-17 June 2011.

11. Linvill, D.; McGee, S.; Hicks, L. Colleges' and Universities' Use of Twitter: A Content Analysis. Public Relat. Rev. 2012, 38, 636-638. [CrossRef]

12. Palmer, S. Characterisation of the use of Twitter by Australian Universities. J. High. Educ. Policy Manag. 2013, 35, 333-344. [CrossRef] 
13. Bélanger, C.; Bali, S.; Longden, B. How Canadian universities use social media to brand themselves. Tert. Educ. Manag. 2014, 20, 14-29. [CrossRef]

14. Kimmons, R.; Veletsianos, G.; Woodward, S. Institutional Uses of Twitter in U.S. Higher Education. Innov. High. Educ. 2017, 42, 97-111. [CrossRef]

15. Tripathi, R. Unofficial' Presence of Higher Education Institutions in India on Social Media: Good or Bad? In Social Media: The Good, the Bad, and the Ugly; Lecture Notes in Computer Science; Dwivedi, Y., Ed.; Springer: Cham, Switzerland, 2016; Volume 9844. [CrossRef]

16. Otto, F.; Williams, S.A. Official use of social network sites by African universities. In Proceedings of the 2 nd Pan African International Conference on Science, Computing and Telecommunications, Arusha, Tanzania, 14-18 July 2014; pp. 46-51.

17. Vaughan, E.; Tinker, T. Effective health risk communication about pandemic influenza for vulnerable populations. Am. J. Public Health 2009, 99 (Suppl. 2), S324-S332. [CrossRef] [PubMed]

18. Hanson-Easey, S.; Every, D.; Hansen, A.; Bi, P. Risk communication for new and emerging communities: The contingent role of social capital. Int. J. Disaster Risk Reduct. 2018, 28, 620-628. Available online: http://www.sciencedirect.com/science/article/pii/S2212420918300517 (accessed on 1 April 2020). [CrossRef]

19. Muniz-Rodriguez, K.; Ofori, S.; Bayliss, L.; Schwind, J.; Diallo, K.; Liu, M.; Fung, I. Social Media Use in Emergency Response to Natural Disasters: A Systematic Review With a Public Health Perspective. Disaster Med. Public Health Prep. 2020, 14, 139-149. [CrossRef]

20. Akter, S.; Wamba, S.F. Big data and disaster management: A systematic review and agenda for future research. Ann. Oper. Res. 2019, 283, 939-959. [CrossRef]

21. Thorne, S. Data analysis in qualitative research. Evid. Based Nurs. 2000, 3, 68-70. [CrossRef]

22. Olsen, T.; Welke, R. Managerial challenges to realizing IT shared services in a public university. Transform. Gov. People Process. Policy 2019, 13, 76-92. [CrossRef]

23. Visvizi, A.; Lytras, M.D. Editorial: Policy Making for Smart Cities: Innovation and Social Inclusive Economic Growth for Sustainability. J. Sci. Technol. Policy Mak. 2018, 9, 1-10.

24. Hsieh, M.Y. The Most Sustainable Niche Principles of Social Media Education in a Higher Education Contracting Era. Sustainability 2020, 12, 399. [CrossRef]

25. Valderrama-Hernández, R.; Sánchez-Carracedo, F.; Alcántara Rubio, L.; Limón-Domínguez, D. Methodology to Analyze the Effectiveness of ESD in a Higher Degree in Education. A Case Study. Sustainability 2020, 12, 222. [CrossRef]

26. Gholami, H.; Bachok, M.F.; Saman, M.Z.M.; Streimikiene, D.; Sharif, S.; Zakuan, N. An ISM Approach for the Barrier Analysis in Implementing Green Campus Operations: Towards Higher Education Sustainability. Sustainability 2020, 12, 363. [CrossRef]

27. Visvizi, A.; Daniela, L. Technology-Enhanced Learning and the Pursuit of Sustainability. Sustainability 2019, 11, 4022. [CrossRef]

(C) 2020 by the authors. Licensee MDPI, Basel, Switzerland. This article is an open access article distributed under the terms and conditions of the Creative Commons Attribution (CC BY) license (http://creativecommons.org/licenses/by/4.0/). 